\title{
Editorial
}

\section{United Nations Public Administration Program Advances e-Development}

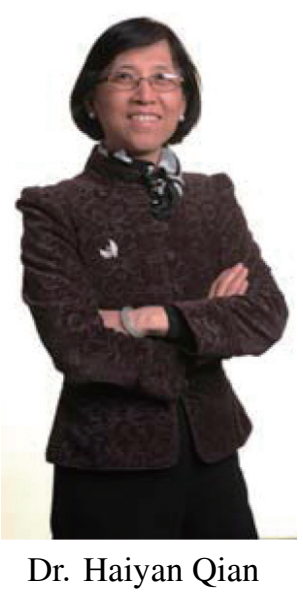

The mission of the UN Program on Public Administration and Development Management (DPADM) of the Department for Economic and Social Affairs (DE$\mathrm{SA}$ ), is to assist Member States is to foster efficient, transparent, accountable and citizen-centric public administrations and public service through innovation and technology. Under the leadership of Dr. Haiyan Qian, the program directs the UN E-Government Survey, con- ducts research, and operates an online training center. Dr. Qian has considerable experience in issues related to public policy and governance. Before joining the United Nations she worked for the Chinese Government serving on the State Science and Technology Commission. She received a Masters in Public Administration from the Kennedy School of Government at Harvard University.

This issue of the Journal features the important achievements of DESA, particularly focusing on the 2011 UN E-Government Survey and provides highlights of three major recent research reports. In preparing the 2011 survey, DESA is addressing challenges and emerging issues, including as user take-up and satisfaction, business architecture for connected or networked government, back office reform, government open data initiatives, universal access to broadband technology and inclusion-participation. The survey results are expected to be released in late 2011.

The dedication and effectiveness of Dr. Qian and the DESA team are highly commendable.

Russell Pipe Editor in Chief 